\title{
A HUMAN PERSPECTIVE ON THE DAILY COMMUTE: COSTS, BENEFITS AND TRADE-OFFS
}

\author{
Professor Glenn Lyons (Director) and Dr Kiron Chatterjee (Senior Lecturer) \\ Centre for Transport \& Society, University of the West of England, Bristol
}

\begin{abstract}
The average worker in Britain spends 139 hours per year commuting - the equivalent of 19 standard working days. While the average distance and time taken for journeys to work has been steadily increasing, the average number of journeys has been decreasing at a similar rate. The aggregate picture inevitably masks an array of underlying trends. This paper offers a multiperspective examination of commuting drawing upon literature in transport, planning, geography, economics, psychology, sociology and medicine. It examines statistical evidence on trends in commuting travel behaviour and finds that one in 25 commuters now travel to work in excess of $100 \mathrm{kms}$ (both ways) and one in ten commuters now spend over two hours per day travelling to and from work. It explores the different impacts (economic, health and social) that commuting has on the individuals that conduct it and seeks to better understand the role of commuting for individuals in today's society. The paper finishes its examination by reviewing the commute experience itself including attitudes towards it and use of time during the journey. The paper concludes by highlighting a dilemma facing transport planning and policy. There are social, economic and financial benefits from an improved travel experience for people with long commute journeys, yet improving travel experience may itself contribute to the trend towards long distance commuting.
\end{abstract}

\section{Introduction}

The term 'commute' has become the shorthand for the daily journey between home and work according to askoxford.com it "derives from commutation ticket, the US term for a season ticket (because the daily fare is commuted to a single payment)". Thus the term emphasises the routine and repeated nature of this journey (initially associated with public transport but now also with the car). As a feature of modern (industrialised) society, commuting has played its part in developing and frustrating the world in which we live. Motorisation and the substantial growth in the use of the private car in the last half a century have given people the 'freedom' to live further from where they work, taking greater advantage of suburban and rural living. Many of our cities and towns are now choked to a greater or lesser extent by the daily exodus from homes to offices and back. Commentators point to the irony of the 'rush hour' as a label linked to commuting.

This paper provides an insight into the daily commute, with a focus on Britain ${ }^{1}$ (though with examination of wider international research findings). Its purpose is to illustrate the different facets and interpretations of commuting. The next section sets a context by providing some key facts and figures which outline the changing nature of commuting. Following this, the paper considers the negative connotations associated with commuting both for the economy and for the individual and their experience and wellbeing. The subsequent section looks at the (changing) way and extent to which the commute influences and is influenced by people's lifestyles and life choices. Against this backdrop, the paper then turns to consider a rather different perspective, namely that of a potentially positive experience of commuting. In concluding, the paper reflects on the possibilities for individuals and society of transforming the commute such that the experience adds to rather than detracts from our daily lives but raises concerns on the trend towards long distance commuting.

\footnotetext{
${ }^{1}$ Differences in available data mean that this paper variously refers to UK and to Britain. To avoid doubt, Great Britain (GB) is comprised of England, Wales and Scotland; as distinct from the United Kingdom (UK) which is comprised of Great Britain and Northern Ireland.
} 


\section{The British commute}

This section of the paper sets the scene by providing a factual account of commuting.

\section{More commuters but less frequent commute trips}

The number of people in employment in the UK since 1971 has increased by 4.1 million to 28.7 million in 2005 (ONS, 2006: p. 50). Most people in employment travel to work. According to the 2001 census, 21.5 million out of the 23.6 million people aged between 16 and 74 in employment in England and Wales commute to work. It may seem obvious to conclude that as the workforce grows, more and more people in Britain will be sharing the commuting experience and contributing to congestion on the roads and crowding on public transport. However, while the number of people in employment has been increasing, the average number of (one-way) commute journeys made per worker per year has decreased from 374 in 1989/91 to 321 in 2002/03 (DfT, 2005a: Table 3.1). Fewer commute journeys can be explained by more people teleworking (an increase in teleworkers ${ }^{2}$ from $4 \%$ to $8 \%$ of the UK workforce between 1997 and 2005), increased availability of flexible working hours (with people working the same hours over fewer days) and longer leave entitlements (ONS, 2006: p. 58). There has also been a sharp increase in the number of workers who occasionally work from home. According to the National Travel Survey in 2002/03 the traditional commute to the same workplace every day applied to $77 \%$ of employed persons $(85 \%$ of women, 70\% of men) (DfT, 2005a: Table 3.6). In a recent survey of 1014 full-time workers in Britain (Lyons et al., 2006), only 62\% travelled to work on all five weekdays in the survey reference week.

While the average number of commute journeys per person has decreased, commuting still dominates our travel. $51 \%$ of adults say that their most frequent journey is the journey to work (for men it is $61 \%$ while for women it is $42 \%$ ) (ONS, 2005: Table A3). For these people, 34\% say that they experience congestion most or all of the time on their commute journey.

Car dominates our commuting travel, except in London

The car dominates commuting travel everywhere except in London (DfT, 2005b: Tables 1.5a, 1.5b, 1.8) and journeys to the city centres of Metropolitan areas where use of the bus is also prevalent (DfT, 2000: Table 3c). For the 3 million commuters living in London, public transport (bus, coach, national rail, underground, light rail, tram) is used as much as the car. In 2004 nearly a million people entered Central London each day in the morning peak by public transport, most of these by rail and underground (DfT, 2005c: Table 1.6).

\section{Our commutes have slowly got longer}

The distance on average we travel to work has been steadily increasing (DfT, 2005a: Table 3.2) from 7.2 miles one-way in 1989/91 to 8.5 miles one-way in 2002/03. It is estimated that it was less than 2.5 miles in 1890 (Green et al., 1999). Rural residents have longer journeys (10.8 miles on average) compared to urban residents (e.g. 6.6 miles on average for Metropolitan areas) (DfT, 2001: Table 6.9). Men's commutes are longer than women's (10.2 miles compared to 6.0 miles) (DfT, 2001: Table 4.3).

National Travel Survey data supplied to us by the DfT has allowed us to consider the variation in commuting trip lengths among the population, rather than simply referring to averages. The trend in the distribution of one-way trip lengths over the last twenty years is shown in Figure 1. It highlights the large decrease in people commuting distances under 2 miles and the large increases in people commuting over 15 miles. This finding is corroborated by Census data which shows that between 1991 and 2001 the percentage of people commuting over $50 \mathrm{~km}$ has increased by $30 \%$ from $2.7 \%$ of those in employment to 3.5\% (corresponding to 825,000 employees in England and Wales) (Nielsen et al., 2005). The Census has also shown that long distance commuters are most commonly found in the areas surrounding London and other Metropolitan cities and are disproportionately represented by managers and senior officials.

\footnotetext{
${ }^{2}$ Teleworkers are here defined as individuals who work mainly in their home or in different places using home as a base and who use a telephone and computer to carry out their work.
} 


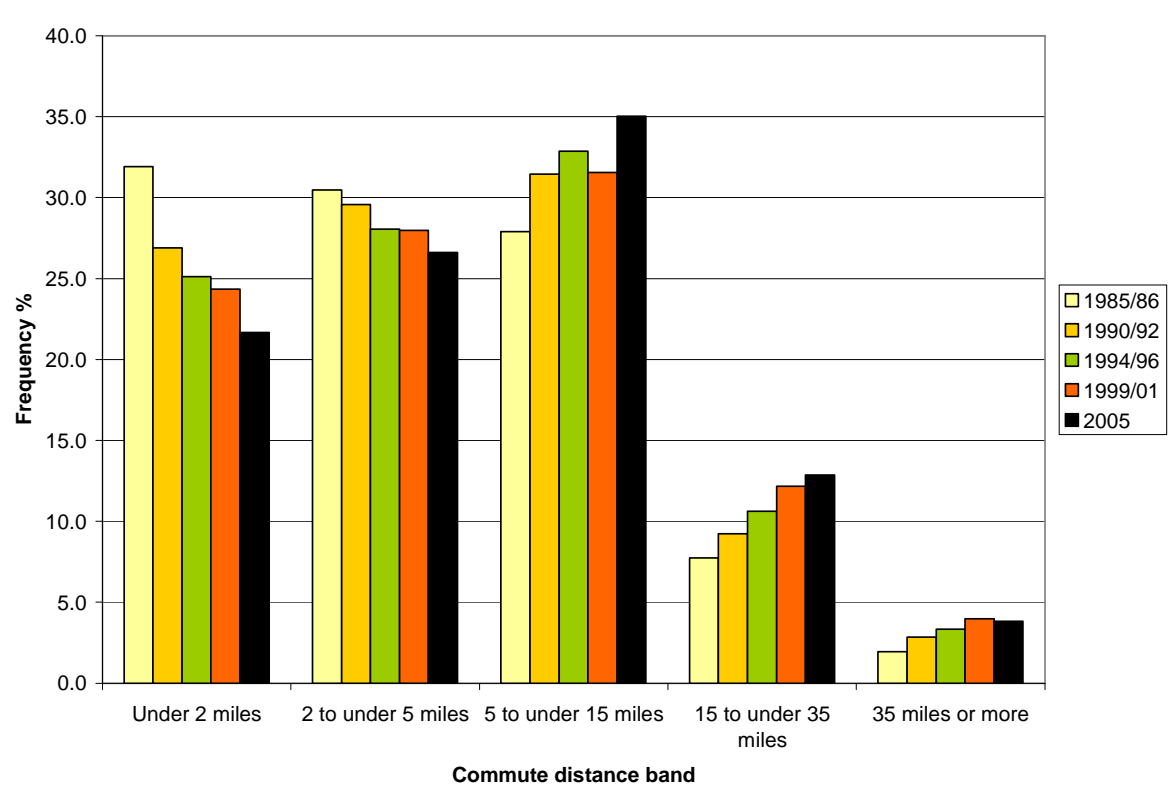

Figure 1 Distribution of one-way commuter trip lengths 1985/86 - 2005 (source: NTS)

Although the length of the average commute has increased, the average number of miles travelled per person per year for commuting and business travel has changed little between 1990 (1975 miles) and 2004 (1950 miles) (DfT, 2005d: Table 4.9a) as a result of the fewer commute trips per person on average mentioned earlier. Between 1994 and 2004 the one-way mean commute time has increased by $10 \%$ from 23.6 minutes to 25.9 minutes (DfT, 2005c: Table 1.8). Across modes, journey time averages vary as follows: rail - 59 minutes (explained by the larger number of these rail journeys that have a destination in London); bus - 35 minute; car - 24 minutes; bicycle - 17 minutes; and on foot - 12 minutes.

Men have journeys that take slightly longer than women (26 minutes compared to 22 minutes in 1998/2000) (DfT, 2001: Table 4.4) but as previously noted their journeys are significantly longer. This highlights that their commute journeys are faster. The average one-way travel time is between 20 and 25 minutes for those people working in the regions outside London and 42 minutes for those working in London (DfT, 2005c: Table 1.9). 11\% of British commuters have a journey of at least one hour - this rises to $31 \%$ for people working in London. Longer commuting times are experienced by those who own homes and work at large offices/plants and those with degrees spend $50 \%$ longer travelling to work than others (Benito and Oswald, 2000).

The average worker commutes 321 times per year and spends 25.9 minutes per journey. This means the average worker spends 139 hours per year commuting - the equivalent of 19 standard working days. London workers spend 225 hours per year commuting - the equivalent of 30 standard working days. In the 1990s commuting times increased substantially for those in London (by 70 minutes per week) and in the south-east (by 50 minutes per week) but were stable outside the south-east (Benito and Oswald, 2000).

\section{Paying the price of commuting}

Further to the previous summary of key statistics on commuting, we now examine various negative aspects of the journey to work.

\section{The monetary cost of congestion and journey delay}

Research suggests that the UK is subject to some of the most extensive congestion in Europe with commuters in the UK (as at 1998) more likely than their European counterparts to encounter congestion $-19 \%$ do so compared to $7 \%$ in France and $4 \%$ in Germany (CfIT, 2001). The cost of congestion is calculated on the basis that time spent travelling is assumed to be wasteful to the economy. Economic appraisal translates time into a monetary value. For travel during the working day, values for each mode of travel are calculated based upon the average wage for an individual using that mode. The official figures include the following: car driver - £26.43/hour; bus passenger $£ 20.22 /$ hour; and rail passenger - £36.96. For travel outside of the working day (including 
commuting) the value of time is determined based upon people's willingness to trade money for time. An official figure of $£ 5.04 /$ hour (at 2002 prices) is currently used as the value of commuting time (DfT, 2004b). This figure is termed an 'equity' value - it averages across the population what people are willing to pay.

The cost of travel is also an important consideration for modelling and forecasting the choicemaking of the travelling public. The basis of choice-making has been taken to be that individuals wish to minimise their 'generalised' cost of travel - with a principal focus on time and monetary cost (Ortuzar and Willumsen, 2001). Some argue that time and cost are simply the most tangible attributes to measure and risk overlooking of other experiential aspects of a journey (Stradling, 2006). Such experiential aspects include physiological and psychological impacts of the journey. These are now examined.

\section{Stress and fatigue}

Kluger (1998) reports that longer car commutes have been found to be positively correlated with high blood pressure, self-reported tension, reduced task performance, negative mood in the evening hours after work and the following symptoms: stiff neck, tiredness, lower back pain, difficulty in focusing attention and anger. There are also impacts on the employer in terms of absenteeism, tardiness, turnover of staff and job satisfaction. Hennessey and Wiesenthal (1999) interviewed 60 drivers in Toronto during a commute journey and found self-reported driver stress and aggression during the journey were increased in high-congestion conditions. Evans, Wener and Phillips (2002) studied rail commuters in New York and found those that perceived their commute as more unpredictable felt greater levels of stress and had evidence of higher elevations of salivary cortisol (secreted by the body in response to physical and psychological stress) but did not have lower motivations in task performance (tested through a proof-reading task).

Main determinants of commuting stress have been identified to be delays caused by traffic volumes, the driving behaviour of other road users (for car users) and unreliability of services (for public transport users). It has been found that commuting is more stressful when there is less control over factors such as traffic congestion, time pressure or the environment within the vehicle. Greater flexibility in working schedules might alleviate some commuting stress - a study of commuters in Atlanta, Georgia, has found evidence for lower driving stress and feelings of time urgency for flexitime commuters (Lucas and Heady, 2002). Gatersleben and Uzzell (2006) have compared the affective responses to commuting of car users, public transport users, cyclists and walkers. Car users were found to perceive their journeys as most stressful and public transport users as most boring. Cyclists were found to perceive their journeys as most interesting and exciting and walkers as most relaxing.

It seems that stress-related impacts of commuting can extend beyond the journey itself. Kageyama et al., (1998) studied the short-term heart rate variability of 223 male white-collar workers in Tokyo and found those commuting more than 90 minutes one-way had chronic stress and fatigue symptoms which can induce cardiovascular abnormalities and dysfunctions related to the inset of heart disease. Walsleben et al. (1999) found rail commuters in Long Island, New York, with long commutes had significantly less nocturnal sleep and increased hypertension. Costa et al. (1988) studied Italian industrial workers and found that commuters (defined as having a journey to work of at least 45 minutes) had restricted free-time and reduced sleeping time.

\section{Health impacts}

Long-term implications of commuting stress for health are not well understood. However, a study of commuters in Kent and Medway attempting to examine this found that those commuting more than 45 minutes one-way reported better health than those commuting less than 45 minutes (Palmer, 2005). Self-reported instances of periods of depression were noted to be lower for those commuting more than 45 minutes compared to those commuting less than 45 minutes. This does not indicate a causal link as there could be intervening factors (such as income) or a reverse link where those suffering periods of depression are unwilling to commute long distances.

There are numerous other potential negative health impacts of commuting beyond stress impacts and these impacts will be more serious as time spent commuting increases. Such impacts are widely reported and include increased risk of involvement in traffic accidents, increased risk of respiratory and cardio-vascular disease due to air pollution, reduced time available for visiting doctor, for leisure and social activities, and for sleep, physical exercise and healthy eating. 
Air pollution from particulate matter in particular is linked to 8,100 premature deaths a year (HDA, 2005) and exposure to this and other pollutants will be related to time spent in and around road traffic. In fact, studies have shown (e.g. Gulliver and Briggs, 2004) that in typical urban conditions car occupants are often exposed to higher levels of all the main air pollutants than pedestrians, cyclists and public transport users. This is a result of the 'trail of pollutants' from vehicles in front. There is increasing evidence that adverse health impacts not only occur due to short-term exposure to high levels of air pollution but due to longer term exposure to lower levels of air pollution. The overall consequence is that exposure to air pollutants through long-term commuting could have significant effect on health over a lifetime.

It has been estimated that adults who are active have $20-30 \%$ reduced risk of premature death and $50 \%$ reduced risk of developing major chronic diseases such as coronary heart disease, stroke, diabetes and cancers (HDA, 2005). It is recommended that people have 30 minutes moderate physical activity a day on five days in a week but this can be difficult to fit into routines involving the working day plus two commute journeys (unless commute journey involves walking or cycling). According to Palmer (2005) a higher percentage of those driving to work by car report a Body Mass Index of over 30 (identified as obese) than those commuting by public transport.

\section{The place of the commute in people's lives}

Having considered negative impacts of commuting, we now seek to better place the journey to work in our lives. How does it fit in with our wider lifestyles and the events over a life time?

\section{The daily routine}

Attempting to characterise the complexity of people's daily routines is challenging due to the enormous variation between individuals and variation for the same individual from one day or week to another. Dix et al. (1983) have offered a depiction of the daily activity-travel routines of households at different lifecycle stages (Table 1). Although society has changed somewhat from the time of their study, these characterisations illustrate how for many working people commuting sits alongside other activities in the household's routines, especially for those with children.

Table 1 Typical weekday routines of working adult(s) in households at different life stages (from Dix et al., 1983)

\begin{tabular}{ll}
\hline Lifecycle group & Weekday activity characteristics \\
\hline $\begin{array}{l}\text { Young adults, no } \\
\text { children }\end{array}$ & $\begin{array}{l}\text { Working hours synchronised between partners, shopping often on journey home } \\
\text { from work, social and leisure outings in evening sometimes direct from work }\end{array}$ \\
$\begin{array}{l}\text { Adults with pre- } \\
\text { school children only }\end{array}$ & $\begin{array}{l}\text { If both partners work one works shorter hours, shopping during working day, } \\
\text { childcare activities at home after work, short period outings occasionally in } \\
\text { evening } \\
\text { Adults with pre- }\end{array}$ \\
$\begin{array}{l}\text { Main earner often works longer hours to increase income, partner usually does } \\
\text { older children } \\
\text { Adults with older } \\
\text { children only }\end{array}$ & $\begin{array}{l}\text { not work, main earner sometimes drops older child off at school, childcare } \\
\text { activities at home after work, escorting older child(-ren) for evening activities }\end{array}$ \\
$\begin{array}{l}\text { Main earner works standard day, partner works part-time to fit in with school } \\
\text { hours and often shops on way home, eating together with children after work, }\end{array}$ \\
$\begin{array}{l}\text { large amounts of chauffeuring, social activity for one partner but not both } \\
\text { Older adults with no } \\
\text { children }\end{array}$ & $\begin{array}{l}\text { Work arrangements independently made, joint shopping trips after return from } \\
\text { work, separate or joint evening social and leisure outings } \\
\text { Part-time working common, working hours synchronised between partners to } \\
\text { some extent, less pressure to combine shopping with journey home from work, } \\
\text { separate or joint evening social and leisure outings }\end{array}$ \\
\hline
\end{tabular}

Darcy et al. (2005) studied 'key' or essential service workers in Sydney, Australia, and found particular difficulties associated with dropping off and picking up children, childcare arrangements and sufficient time to spend with children for those workers with long commute journeys. They also suggested difficulty in affording a home close to the workplace was preventing some workers starting a family. Employers acknowledged fatigue, high commuting cost, lateness and absenteeism were affecting staff with long commutes and subsequently staff retention.

Statistics confirm that for many commuters there are other journeys that also need to be organised as part of the working day. This is much more the case for women who are more likely to follow a commute/business journey with a shopping, escort or social trip $(21 \%)$ than men (12\%) (DfT, 
2005a: Table 3.3). These additional journeys often represent household/family demands that can add considerable pressure to people's lives.

The daily commute may not be as 'routine' as it is perceived to be. Of a national survey of 791 car drivers (Stradling et al., 1999) it was found that $69 \%$ of employed car drivers drive to work every working day with $23 \%$ driving less frequently than this and $9 \%$ never or almost never driving to work (these could be working at/from home). Whilst $69 \%$ drive to work every working day, only $44 \%$ drive to work every day in the rush hour.

\section{Life course}

The nature of commuting for an individual will change over time. Analysis of the British Household Panel Survey (1991-2001) shows that $20 \%$ of workers change job or residence each year and $18 \%$ of workers change commute mode of transport from one year to the next (Dargay and Hanly, 2004). Over a ten year period of working it is found one half of people change their main method of travel at least once and one in five switch three or more times (Dargay and Hanly, 2003). When workers change jobs and/or home or both it is found that just as many increase their commute time as decrease it (Dargay and Hanly, 2003). As would be expected, those individuals with long commute times are more likely to reduce their commute times and those with short commute times are more likely to increase their commute times. $56 \%$ of individuals commuting to work over 60 minutes one-way in one year are found to decrease their commute time by at least 5 minutes the following year.

A study of the 10 year history of commuting of 40 workers in Bristol (Mason, 2005) found that periods of time in people's lives with long commutes (over one hour) tended to be short in duration (one to two years) before a job or home move took place. However, when the Bristol commuters were asked whether they were willing to commute further to obtain the job they wanted about half agreed. However, when asked if they were prepared to move house to do so, very few agreed. The Government's 2004 White Paper on Transport notes this preference with the statement 'more people remain in the same place even if they change jobs, rather than move nearer to where they work' (DfT, 2004a: p. 21). This highlights that decisions on where to live and to work are influenced by factors beyond the journey to work (the cost and quality of housing, the quality of neighbourhood, the absence of crime and access to schools, family and friends) and a trade-off will be made between factors.

A major social trend in recent years has been the increase in dual-earner households and Green et al. (1999) highlight the variety of reactions of these households in response to a job relocation of one household member. Many such households elect to avoid moving home to minimise the impacts on a partner's career and the disruptive effects of a move on children's education. The person relocating their job will accept instead either a longer daily commute, a long distance weekly commute or a regime somewhere between these (e.g. commuting on certain days only).

\section{Tolerating the commute}

Some insight has been provided on why people put up with long commutes given the economic, psychological and physiological costs of commuting. When asked why they do not live closer to work, motorists commuting for at least 10 minutes one-way most often stated that they liked the area in which they live (28\%) or have never thought about it $(27 \%) .7 \%$ said they like to separate home and work. When asked the maximum time they would be prepared to travel respondents on average said they would be prepared to travel nearly twice as long as currently - up from 18 minutes to 35 minutes on average (Lex, 1999). Ory et al. (2004) found a paradox in that those people valuing time with their families tend to dislike commuting but those in large households tended to like commuting. This indicates that many commuters value the time spent commuting as time away from pressures of work and home.

A study in the Netherlands found that once one-way commuting journeys exceed 50 minutes people are much more likely to search for another job. Below this, it is implied people tolerate or are content with their commuting time. (van Ommeren, 1996). Wachs et al. (1993) found from a study of 1,500 employees in Southern California that commute satisfaction declines as commute journey time increases with 46 minutes the threshold where responses shift from being satisfied to dissatisfied.

Economics theory would assume that long journey time commuters must be compensated for by an intrinsically or financially rewarding job or by the benefits of living in a preferred residential 
environment. Therefore it would be expected that subjective well-being would be the same regardless of an individual's commuting time. However, Stutzer and Frey (2004) identify the 'commuting paradox' - people with longer commuting times report systematically lower subjective well-being, measured in terms of satisfaction with life. These findings of low satisfaction with long commutes support the notion that a long commute may be accepted as a short term resolution (given associated home or job benefits) but that changes are likely to be sought in the longer term to home, job or travel arrangements to arrive at a more agreeable state.

\section{Commuting time as a gift rather than a burden}

In the field of transport studies, travel is treated as a derived demand - commuting is derived from the need to get to and from work. It has tended to follow that the act of travelling itself is the cost that must be suffered in order to attain the benefits or utility of the activity at the destination. More recently, however, there has been growing interest in the notion that there might be other benefits to travel concerned with the journey itself.

\section{Positive utility}

Mokhtarian and Solomon (2001) suggested that there are potentially three sorts of beneficial activities arising from travel: those conducted at the destination; those undertaken while travelling; and the activity of travelling itself. They note (Mokhtarian and Salomon, 2001, p. 702) that time use while travelling can include 'anti-activity' - "the ability to use the time for relaxing or thinking, including 'shifting gears' mentally between origin and destination activities and roles". With regard to the act of travelling itself, the benefit to the individual can be "a consequence of intrinsic aspects of travel itself. . . the sensation of speed, movement through and exposure to the environment, the scenic beauty or other attraction of a route" (Mokhtarian and Salomon, 2001, p. 703).

To underline this notion of the 'positive utility' of travel, a survey of San Francisco Bay residents in California examined their views on travel. Of the 1900 respondents, more than two-thirds were found to disagree with the statement "the only good thing about travelling is arriving at your destination" and nearly half agreed with the statement "getting there is half the fun" (Mokhtarian and Solomon, 2001). The 1384 commuters in the sample were asked: "Some people may value their commute time as a transition between home and work, while others may feel it is stressful or a waste of time. For you, what would be the ideal one-way commute time?" The average response was an ideal commute of just over 16 minutes.

Conceptualising the productivity of travel time use

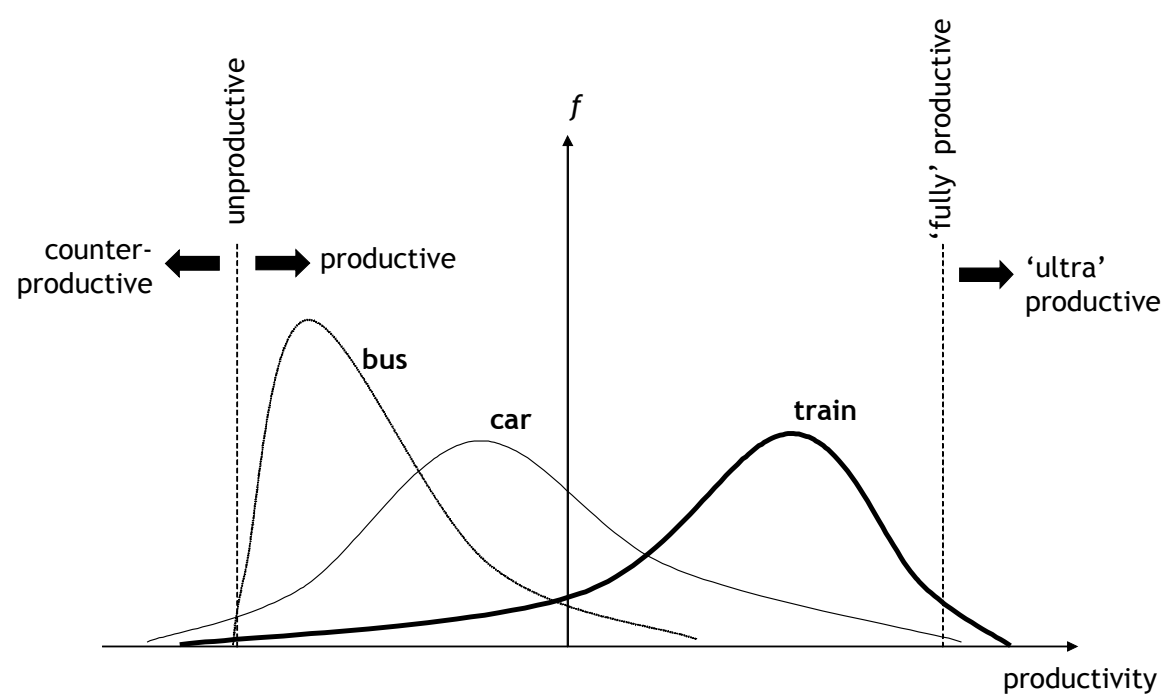

Figure 2 Illustrative frequency distributions of 'productivity' of travel time by mode (reproduced from Lyons and Urry (2005))

Turning to the use and value of travel time itself, conceptually it can be imagined that the extent of benefit of travel time use varies across individuals, journey types and modes of travel. Figure 2 illustrates this. Counter-productive travel time represents time use that not only achieves no benefit in itself but also has an adverse effect on time use beyond the journey (e.g. a stressful commute 
journey affects an individual's level of productivity once they reach work). Unproductive travel time is that where an individual has achieved no benefit - in other words the travel time is wasted time. Productive travel time reflects a use of time that has been of some benefit to the individual. 'Fully' productive travel time indicates that the use of time on the journey has been as beneficial as that time would have been if used otherwise. 'Ultra' productive travel time indicates that the use of time on the journey has been more beneficial than had that time been used otherwise (e.g. getting more work done because of the lack of interruptions which tend to disrupt thinking in the office).

While distributions such as those in Figure 2 may be conceptually appealing, they are difficult to calibrate based on real-life measurement. An awareness of the need to value our travel time in a more refined manner than treating it as wasted time has been around for many years. In 1977 Hensher put forward a formula for the value of business travel time. This seeks to account for how productive work while travelling could offset the benefits of saving travel time, while also accounting for how any saved time might be used and valued. Though some attempts have been made to populate this and similar formula (see Fowkes, 2001), some of the terms within the formula remain difficult to quantify.

\section{The information age}

While positive use of travel time will vary across individuals and circumstances it may also be changing over time. In the 1970s we had not yet encountered the full force of the information age. Thirty years on and the travelling environment in some respects is now very different. Laptops hold the equivalent of vast filing cabinets full of paper documentation. MP3 players have reduced bulky record collections into pocket-sized entertainment systems for people on the move. Mobile phones are transforming communication as we are no longer restricted to connecting place to place but are able to connect person to person (Little, 2006). Blue-tooth technology allows the car driving commuter too to make use of new devices in the vehicle. It might be supposed that a transformation of the commute experience is now therefore being made possible.

\section{The time use of rail commuters}

A recent UK survey of 26,221 rail passengers (Lyons et al., 2007) included a set of questions about travel time. About a third of rail journeys are for commuting. The survey asked respondents to indicate what activities they engaged in and which single activity they spent most time engaged in during their journey. Table 2 shows the most popular responses for commuters.

Table 2 Comparison, by direction of travel, of the percent of travellers undertaking activities for some time during a train journey and (shown in brackets) for most of the time

\begin{tabular}{lrr}
\hline activity & out & return \\
\hline reading for leisure & $62(42)$ & $62(42)$ \\
window gazing/people watching & $49(12)$ & $48(11)$ \\
working/studying & $27(13)$ & $29(13)$ \\
talking to other passengers & $11(4)$ & $10(3)$ \\
sleeping/snoozing & $16(5)$ & $23(5)$ \\
listening to music/radio & $12(4)$ & $13(5)$ \\
\hline
\end{tabular}

The survey also addressed the matter of 'positive utility'. It asked 'Thinking about the time you spent on the train after being given a copy of this questionnaire, which one of the following statements do you most agree with?'. Commuters responded as follows: 'I made very worthwhile use of my time on this train today' $-22 \%$; 'I made some use of my time on this train today' $-53 \%$; and 'my time spent on this train today is wasted time' $-22 \%$. Most of the nation's rail commuters it seems are getting something positive from their travel time. This said, nearly 1 in 4 commuters believe it to be wasted time. The research (ibid) looked further into specific activities across journey purposes. For instance, $59 \%$ of commuters whose main activity was sleeping/snoozing considered their train journey time of some use or very worthwhile. This figure increases to $83 \%$ for reading for leisure and $95 \%$ for working/studying. Even for window gazing/people watching the figure is $55 \%$.

An illuminating issue is that of whether people plan in advance how to use their rail travel time. Overall across journey purposes, $13 \%$ had planned 'a lot', $41 \%$ 'a little' and $47 \%$ 'not at all'. The figures were similar for commuters specifically. Comparison of advance time use planning with the extent of worthwhile time use revealed that those passengers who considered their travel time to have been wasted were more than twice as likely to have done no advance planning (70\%) than those who consider their travel time to have been very worthwhile (31\%). 
In terms of the impact of the information age, over $70 \%$ of rail commuters have a mobile phone with them, while less than $10 \%$ have a laptop. (Meanwhile, over $40 \%$ of commuters have a reading book and over $80 \%$ have a newspaper.) When asked whether such items to hand are actually used during the journey, substantial proportions indicate not. Thus many people are equipped in ways that provide possibilities to use time in different ways, even though they may not do so.

\section{The time use of car drivers}

Similar survey data are not available for car commuters, although $15 \%$ of British motorists in a RAC survey said they use their car as a mobile office/crèche (RAC, 2001). A rare insight into the experiences of the car based mobile worker is however provided by Laurier (n.d.) who shadowed six individuals, each for a week. He observed that "Once out on the road, company employees in their cars now recreate the sociability of their office and the culture of their organisations in their cars via the skilful use of mobile telephony and conversational interactions." Unexpectedly he also found that "car-based workers often make highly productive use of time spent stuck in slow-moving traffic. This potentially stressful and otherwise unproductive situation is used instead to check-up on paperwork, make numerous phone-calls to their other team members and prepare themselves for subsequent meetings with clients". Bull (2004) has also pointed to the pleasurable experience of visually connecting in one's car with the passing landscape accompanied by the car stereo.

\section{The psychology of commuting}

Stradling (2006) refers to the different forms of effort required in making a journey: physical, cognitive and affective effort. He notes that "route familiarity will reduce the "cognitive spend". Affective effort concerns emotions aligned to uncertainty or worry. One might thus deduce that for most commute journeys, cognitive and affective effort will be low - the routine and familiarity allow the individual to enact the journey almost sub-consciously or on 'auto-pilot'. This may be true even where the journey might appear to others to be disrupted. If roadworks or an accident have caused unexpected tail-backs on a particular journey then this is likely to increase affective effort and, if rerouting of the journey is then called for, greater cognitive spend may result. If, however, one knows for the daily commute that every day at a certain junction one will meet a queue of traffic then this is part of the ritual of the commute and may not encroach upon cognitive or affective effort. This would seem to suggest that commuting could be the very journey setting in which one has greatest capacity to turn attention to fruitful travel time use.

\section{The gift of travel time}

Jain and Lyons (n.d.) conducted a series of focus groups to probe people's views, across travel modes, on the matter of the journey experience. From this has emerged the notion of seeing travel time as a gift. In some respects the gift is the 'sacrifice' of time by the individual in order to be present at an alternative location, as expected or desired by a third party (such as family and friends or, in the case of commuting, the employer). Three forms of positive travel time experience are identified: transition time, time out and equipped time.

\section{Transition time}

Transition time can be seen in two ways: the need to physically experience crossing space in time to achieve the sense of distance and difference; and the temporal opportunity to translate, adjust or prepare oneself for a different social setting and social identity at the destination. Transition time appears to be a key reason for people rejecting the prospect of teleportation (i.e. zero commute time: Mokhtarian and Salomon (2001)).

\section{Time out}

Regardless of mode, travelling can provide an impermeable 'protected' space away from the world around. Whether public or private transport, commuting can hold the prospect of being 'alone' (even if in the presence of others where such individuals are strangers). The space can, however, become less permeable. One may make friends through encountering them on the commute if by collective transport. Mobile communications devices can, if permitted, also permeate the space. However, in a positive sense, time out can be seen as 'time for' - the commuter can choose how this time is spent. As a consequence, when 'alone' on their journey, many commuters relate to this as time for 'doing nothing'. Time out is a reprieve from the different roles assumed in life.

\section{Equipped time}

It has been noted that travellers are become increasingly equipped to use time when on the move (as discussed for rail above). The information age provides a myriad of opportunity, supplementing 
the traditional travel objects of paperwork, books and newspaper. The mobile phone in particular appears an invaluable companion for some individuals in its ability to connect them to remote others and allow them to 'reinvest' time in maintaining their social networks (Larsen et al., 2006).

\section{The long distance commuter and transforming the commute}

The research examined in this paper reveals a diverse set of issues relating to the daily commute. The complex and individualised nature of the commute and associated lifestyle and situational circumstances makes it difficult to make definitive statements about commute costs and benefits. Many experiences and impacts of the commute are also subjective in nature or difficult to quantify. Nevertheless, the paper has sought, in many respects, to highlight the two sides of the coin that is the daily commute. On the one side, the commute can be seen as a blight on society in terms of its imposition of traffic and pollution and thus economic, environmental and social costs and on the individual in terms of sacrificed time, the burden of cost and the potential physiological and psychological impacts of stress and effort (physical, cognitive and affective). On the other side, the commute can offer a journey with low cognitive and affective effort and represent a daily pocket of time that can fulfil an important social function in terms of the opportunity it presents for transition between life roles ('gearing up' and 'winding down') and for time out.

The statistical evidence has shown that one in 25 commuters in Britain now travel to work in excess of $100 \mathrm{kms}$ (both ways) and one in ten commuters now spend over two hours per day travelling to and from work. Although overall commuting distance is not growing (due to fewer commute journeys per person), the trend of lengthening individual journeys (with many being carried out by car) has significant implications. These include adding to traffic on inter-urban road and rail networks, offsetting reductions of traffic from other initiatives, thwarting planning policies aimed at creating self-contained communities and impacting adversely on family life.

Without new policies, the Department for Transport (DfT, 2004a) forecast that traffic on English roads will have increased by between $38 \%$ and $53 \%$ by 2025 (from 2000 levels) and that rail passenger numbers will have increased by between $50 \%$ and $73 \%$. This suggests that journey times and unreliability for commuting journeys on road and rail will increase. Headicar and Curtis (1998) have found in a study of residents in four new estates in Oxfordshire that work-related travel accounts for the majority of differences in car travel distance among residents which implies that influencing commuting distance could have large potential to impact on overall travel behaviour and traffic. This indicates that further research is warranted to better understand long distance commuting. Many studies have used cross-sectional data sets to examine variation in commuting behaviour at a particular point in time. What would be beneficial is to conduct in-depth longitudinal studies of long distance commuters to find out what circumstances have led them to this practice and to examine their motivations to continue with this practice or to seek to curtail it. We suggest an approach involving in-depth interviews and the collection of commuting biographies will be fruitful in this research aim.

Beyond the concerns over the increasing prevalence of long distance commuting, an important message that can be drawn from this examination of the daily commute is that all individuals have choices when it comes to commuting. For some, though not all, there will be the choice not to commute and to work from home instead. There are many individuals who can choose how and at what time they undertake the commute in order to fit in with other commitments or to avoid traffic. Recent research reveals that a significant proportion of full-time workers practise some days of mixed home/workplace working (Lyons et al., 2006). With continuing Government investment in transport, there is the prospect of an increase in the attractiveness of different modes of travel, thereby offering greater choice of how to commute.

Yet many individuals may suggest that such choices are not available to them - they are bound into an habitual or routine commute pattern. For many people the commute takes a considerable amount of time out of their day and results in stress, fatigue and general dissatisfaction. However, almost everyone has the opportunity to exercise at least some choice over the travel time experience of commuting. Recent research outlined in this paper suggests that there is a link between more thought given by individuals to how they use their travel time and how worthwhile they find their travel time to be. The information age is equipping us to perhaps have more things at our disposal to do when on the move. However, even in the absence of the technology there is the choice of how to capitalise on commuting for transition time and for time out. 
Our review of the human perspective of commuting raises a dilemma for transport planning and policy. There are social, economic and financial benefits from improving the travel experience for people with long commute journeys, yet improving the travel experience may itself contribute to the trend towards long distance commuting. The challenge may be seen therefore as introducing effective measures to reverse the trend of long distance commuting (involving planning policies and economic instruments, for example), whilst supporting the transport industry in enhancing the travel experience for commuters and other travellers.

\section{References}

Benito, A. and Oswald, A.J. (2000). Commuting in Great Britain in the 1990s. University of Warwick.

Bull, M. (2004). Automobility and the Power of Sound. Theory, Culture and Society. 21(4/5), 61-79.

CfIT (2001). European Best Practice in the Delivery of Integrated Transport - Report on Stage 1: Benchmarking. A report prepared by WS Atkins for the Commission for Integrated Transport.

Costa, G., Pickup, L. and Di Martino, V. (1988). Commuting - a further stress factor for working people: Evidence from the European Community. II. An empirical study. International Archives of Occupational and Environmental Health, 60(5), 377-385.

Darcy, M., Stubbs, J., Perry, J. and Blunden, H. (2005). Moving to work, moving from work: Housing, travel, cost, and key workers in Sydney. Paper presented at Australian Social Policy Conference, UNSW.

Dargay J. and Hanly, M. (2003). Travel to work: An investigation based on the British Household Panel Survey, paper presented at NECTAR Conference No. 7, Umeå, Sweden.

Dargay J. and Hanly, M. (2004). Volatility of car ownership, commuting mode and time in the UK, paper presented at the World Conference on Transport Research, Istanbul, Turkey.

DfT (2000). Transport Statistics Bulletin: Transport Statistics for Metropolitan Areas 2000 Edition.

DfT (2001). Focus on Personal Travel 2001 Edition.

DfT (2004a). The Future of Transport: A network for 2030. Transport White Paper.

DfT (2004b). Values of Time and Operating Costs. TAG Unit 3.5.6.

DfT (2005a). Focus on Personal Travel 2005 Edition.

DfT (2005b). Regional Transport Statistics 2005 edition, November.

DfT (2005c). Transport Statistics Great Britain 2005.

DfT (2005d). Transport Trends 2005 Edition.

Dix, M.C., Carpenter, S.M., Clarke, M.I., Pollard, H.R.T. and Spencer, M.B. (1983). Car Use: A Social and Economic Study. Gower, Aldershot.

Evans, G.W., Wener, R.E. and Phillips, D. (2002). The morning rush hour: Predictability and stress, Environment and Behaviour, 34(4), 521-530.

Fowkes, A. S. (2001). Principles of Valuing Business Travel Time Savings. Working Paper 562, Institute for Transport Studies, University of Leeds.

Gatersleben, B. and Uzzell, D. (2006). Affective appraisals of the daily commute: comparing perceptions of drivers, cyclists, walkers and users of public transport. In press.

Green, A.E., Hogarth, T. and Shackleton, R.E. (1999). Longer distance commuting as a substitute for migration in Britain: A review of trends, issues and implications. International Journal of Population Geography, 5, 49-67.

Gulliver, J. and Briggs, D.J. (2004). Personal exposure to particulate air pollution in transport microenvironments. Atmospheric Environment, 38, 1-8.

HDA (2005). Making the Case: Improving Health through Transport. Health Development Agency.

Hennessy, D.A. and Wisenthal, D.L. (1999). Traffic congestion, driver stress and driver aggression. Aggressive Behavior, 25, 409-423.

Headicar, P. and Curtis, C. (1998). The location of new residential developments: its influence on car-based travel. In Banister, D (ed) Transport Policy and the Environment, E \& FN Spon, London, pp 222-42.

Hensher, D. A. (1977). Value of Business Travel Time. Pergamon Press, Oxford. 
Jain, J. and Lyons, G. (n.d.). The gift of travel time. Forthcoming in Journal of Transport Geography.

Kageyama, T., Nishikido, N., Kobayashi, T., Kurokawa, Y. Keneko, T. and Kabuto, M. (1998). Long commuting time, extensive overtime, and sympathodominant state assessed in terms of short-term heart rate variability among male white-collar workers in the Tokyo megalopolis. Industrial Health, 36(3), 209-217.

Kluger, A.V. (1998). Commute variability and strain. Journal of Organizational Behaviour, 19, 147165.

Larsen, J., Urry, J. and Axhausen, K. (2006). Mobilities, Networks, Geographies. Ashgate, Aldershot.

Laurier, E. (n.d.). 'Meet you at junction 17': a socio-technical and spatial study of the mobile office. ESRC Report.

Lex (1999). The 1999 Lex Report on Motoring. Lex Service PLC, Bourne End.

Little, S. (2006). The Intersection of Technology and Society: evaluating the impact of intelligent infrastructure on transport and travel. Review for the Foresight 'Intelligent Infrastructure Systems' project, Office of Science and Technology, Department for Trade and Industry.

Lucas, J.L. and Heady, R.B. (2002). Flextime commuters and their driver stress, feelings of time urgency, and commute satisfaction. Journal of Business and Psychology, 16(4), 565-571.

Lyons, G. and Urry, J. (2005). Travel time use in the information age. Transportation Research, 39(A), 257-276.

Lyons, G., Haddad, H. and Jones, T. (2006). Introducing consideration of varied spatiotemporal workers to the study of teleworking. Paper presented at 11th International Conference on Travel Behaviour Research, Kyoto.

Lyons, G., Jain, J. and Holley, D. (2007). The use of travel time by rail passengers in Great Britain. Transportation Research, 41(A), 107-120.

Mason, V.A. (2005). Changing Commute Distances. Masters dissertation. UWE, Bristol.

Mokhtarian, P.L. and Salomon, I. (2001). How derived is the demand for travel? Some conceptual and measurement considerations. Transportation Research A 35, 695-719.

Nielsen, T.S., Hovgesen, H.H. and Lassen, C. (2005). Exploratory mapping of commuter flows in England and Wales. Paper presented at RGS-IBG Annual International Conference, London.

ONS (2005). Omnibus Survey November 2005: Table A3. Interviewed a random probability survey of 1,147 adults aged 16 and over living in private households in England, Scotland and Wales. Available from www.dft.gov.uk.

ONS (2006). Social Trends No. 362006 edition. Office for National Statistics.

Ortuzar, J. de D., and Willumsen, L. G. (2001). Modelling Transport (Third Edition). Wiley, Chichester.

Ory, D.T., Mokhtarian, P.L., Redmond, L.S., Salomon, I., Collantes, G.O. and Choo, S. (2004). When is commuting desirable to the individual. Growth and Change 35(3), 334-359.

Palmer (2005). Health of people who travel to work: the effect of travel time and mode of transport on health. Unpublished paper. University of Kent.

RAC (2001). RAC Report on Motoring 2001. RAC Motoring Services, Feltham.

Stradling, S.G., Meadows, M.L. and Beatty, S. (1999). Factors Affecting Car Use Choices. Report to Department of the Environment, Transport and the Regions.

Stradling, S. (2006). The psychology of travel. Review for the Foresight 'Intelligent Infrastructure Systems' project, Office of Science and Technology, Department for Trade and Industry, London.

Stutzer, A. and Frey, B.S. (2004). Stress that doesn't pay: The commuting paradox. IZA Discussion Paper No. 1278. IZA (Institute for the Study of Labor), Bonn, Germany.

van Ommeren, J. (1996). Commuting and Relocation of Jobs and Residences: A Search Perspective. Tinbergen Institute Research Series. Thesis Publishers, Amsterdam.

Wachs, M., Taylor, B.D., Levine, N. and Ong, P. (1993). The changing commute: a case- study of the jobs-housing relationship over time. Urban Studies, 30(10), 1711-1729.

Walsleben, J.A., Norman, R.G., Novak, R.D., O'Malley, E.B., Rapoport, D.M. and Strohl, K.P. (1999). Sleep habits of Long Island rail road commuters, Sleep, 22(6), 728-734. 